\section{BIOCHEMICAL IMPORTANCE OF INDIVIDUAL AMINO-ACIDS}

$\mathrm{T}$

HE biological importance of a protein is dependent on the extent to which it is able to supply the amino-acids which the animal cannot synthesize for itself. Willcock and Hopkins (1906-7) showed that young mice, fed on a diet in which zein was the sole protein, lost weight and died in about 17 days. The addition of tryptophan to the diet enabled the mice to survive for longer periods, although they continued to lose weight. In 1914, Osborne and Mendel repeated the experiments and found that, in growing rats, the addition of tryptophan enabled the animals to maintain their normal weights, and that with the further addition of lysine normal growth was restored. Tryptophan and lysine were therefore regarded as essential amino-acids, the list of which was afterwards extended to include histidine, threonine, valine, phenylalanine, leucine, isoleucine and methionine or possibly cysteine. The discovery of threonine by Rose (1931) was the direct outcome of experiments involving the feeding to rats of synthetic mixtures of all the amino-acids known at that time. The rats failed to grow, and Rose concluded that proteins probably contain an unknown amino-acid, which was afterwards isolated and identified as $\alpha$-amino- $\beta$-hydroxy- $n$-butyric acid (threonine).

Essential amino-acids then, in common with vitamins, cannot be synthesized in the mammalian body and have to be supplied in the diet. Unlike vitamins, which are present in small quantities in the tissues, amino-acids, combined in proteins, form a large part of the total mass of the body, and the quantitative requirements of essential amino-acids are therefore considerably greater than those for vitamins. The deleterious effect of a dietary deficiency of a particular amino-acid will be less marked and sudden, therefore, in the adult animal, due to the great store of amino-acids which the body has in its proteins.

Essential amino-acids may have different biological functions. One may be needed only as a building material for the synthesis of protein, in which case a lack of that amino-acid in the diet will result only in an inhibition of protein synthesis, the severity of the symptoms from which will depend on the quantitative requirements of the body relative to its stores of that amino-acid. Another may be indispensable because of its role as a precursor of, for example, a ductless gland secretion, such as adrenaline, which is probably derived from phenylalanine. Cysteine or methionine are the principal sources of sulphur to the animal body, and are probably precursors of glutathione, taurine, insulin, keratin, etc. Valine deficiency in rats produces characteristic nervous symptoms, involving extreme sensitivity to touch and severe lack of co-ordination of movernent, suggesting a special role of this amino-acid in the central nervous system. The precise part played by tryptophan is still a matter of conjecture, but from the severe effects which follow its removal from the diet, it seems evident that it has some special function to perform apart from protein synthesis. Its effect on the growth of one of the simpler invertebrates, Obelia, suggest that it may control the speed of metabolism. Histidine is probably the precursor of histamine, ergothionine, carnosine and anserine (found in goose muscle). Lack of lysine produces no specific symptoms apart from cessation of growth, although animals kept on lysine-deficient diets are not static as regards the development of individual tissues and organs. Thus body, tail and leg bones increase.in length, and organs such as eyes and kidneys increase in weight, while others, such as muscle, decrease. Although male genital organs are unaffected, the œstrus-cycle may be suspended. Lysine is thus probably required as a purely passive material for the synthesis of protein.

H. A. Harris, A. Neuberger and F. Sanger (Biochem. $J ., 37,508$; 1943) have recently shown that lysine deficiency in rats produces cessation of growth and hypoproteinæmia. The number of red cells and the amount of hæmoglobin per unit volume of blood are slightly less than in the controls, and this is interpreted as indicating not so much an anæmia proper as a retarded development of the hæmopoietie system. A comparison of the radiographs of the control and lysine-deficient rats showed great differences in the bodily dimensions. Normals are well covered with subcutaneous fat and muscle as compared to the lysine deficients, in which the degree of calcification in all bones is generally reduced. The epiphyseal cartilage of the long bones is barely visible and histological examination reveals considerable reduction in the number of chondroblasts in the first zone of proliferating cartilage. In the zone of calcified cartilage, the trabecula of calcified matrix are heavier in the deficient animals than in the controls. Mitotic figures in the testes are reduced as compared with controls.

The changes observed are assumed to be due to a general inhibition of protein formation, leading to reduced growth of some organs which develop at the expense of others not unlike the picture produced by ordinary starvation. Protein is transferred according to a fixed system of priorities, and the sum total of these changes is constant body weight, although the animal is no longer the same animal. It is noteworthy that lack of one essential building unit in the diet produces essentially the same symptoms as underfeeding, and if only one essential amino-acid is missing from a protein then that protein is rendered unsuitable as the sole source of nitrogen in the diet of the young or adult animal. Cadet de Vaux in Paris during the French Revolution tried to persuade the poor that gelatin soup was a satisfactory and nutritious diet. The poor refused, and their attitude has since been shown to have been amply justified, as gelatin contains no valine, isoleucine or tryptophan. T. F. DIXoN.

\section{BRITISH ELECTRICAL AND ALLIED INDUSTRIES RESEARCH ASSOCIATION}

THE twenty-second annual report of the British Electrical and Allied Industries Research Association (E.R.A./T341) summarizes the work which has been carried out during the year ended September 30 , 1943 , and again lists, hy titles, the various research reports which have been issued during the year. The work is reviewed under the same eighteen major classifications as last year, among which dielectrics, cables and overhead lines, electric control apparatus, and magnetic materials figure largely.

The report shows that the work of the Association has been carried on during the year by 108 active technical sections, sub-committees and panels formed from workers in industry and academic institutions. 